\title{
Jung at heart
}

\section{Rick Clarke}

I was wandering through the ward clutching an auroscope in search of a patient suffering from severe psychological and behavioural problems who was complaining, inter alia, of a blockage in her ears. I encountered her consultant, a Jungian, who when informed of my purpose, responded that this was the most important development in years as it meant she was ready to listen! Several years later I came across a very similar patient, who by coincidence, had been referred to the national unit where I was working by the aforementioned consultant. This patient's repertoire of disturbed behaviour included swallowing various exotic items. However, on being told at the ward round that he had swallowed $12 p$ in small denomination coins I was fortunately able to conclude that here again was a most important development - it meant he was ready for change!

Rick Clarke, Senior Registrar, Guy's Hospital, St Thomas Street, London SEl 9TR 